Article

\title{
Patterns and predictors of complementary and alternative medicine use in people presenting with the non-communicable disease in an urban health facility, North India
}

\author{
Devashish Nailwal, ${ }^{1}$ Venkatashiva Reddy B, ${ }^{2}$ Arti Gupta ${ }^{3}$ \\ ${ }^{1}$ Veer Chandra Singh Garhwali Government Medical Sciences and Research Institute, Srinagar, Uttarakhand; \\ ${ }^{2}$ Department of Community Medicine, NRI Academy of Medical Sciences, Guntur, Andhra Pradesh; ${ }^{3}$ Department \\ of Community and Family Medicine, All India Institute of Medical Sciences Mangalagiri, Andhra Pradesh, India
}

\begin{abstract}
Background: The rising burden of non-communicable diseases (NCDs) is a threat to India. Increasingly, individuals interested in improving their health and making healthy lifestyle changes are turning to complementary and alternative medicine (CAM) as a health-care option.

Design and Methods: The objective of this study was to determine the prevalence, pattern, and predictor of alternative medicine use among NCDs patients undergoing allopathic treatment in an urban health centre. The study design was a hospital-based crosssectional study, which was done in a government hospital, Srinagar, Pauri District, Uttarakhand, India among adult males and females aged above 20 years. The patients having NCDs were systematically sampled.

Result: Among 233 studied patients 57.1\% were males. The mean age of the patients was 55.8 years (SD 13.5). Of the total studied patients $46.8 \%$ were diagnosed with DM, and $43.8 \%$ of HTN. Nearly one-fifth of the patients were known to have a CVD or COPD. A total of $49.8 \%$ of the studied NCD patients reported use of both allopathic and alternative medicine treatment and nearly $3.4 \%$ of the studied NCD patients in the last one year to seek exclusive alternative medicine treatment. The overall use of exclusive alternative medicine was low that is $3.7 \%, 1.0 \%$, and $5 \%$ in diabetes, hypertension, and chronic lung disease patients, respectively. The most common form of alternative medicine used by studied patients was medicinal herbs/biological-based medicine (MB) (62.9\%). Among MB commonly used were a bitter gourd, aloe vera, and others. $29.8 \%$ of the patients used Indian/Ayurveda medicine in total.

Conclusions: The use of exclusive alternative medicine is low in adult patients with NCD. However, medical pluralism is prevalent. A better understanding of practices especially that focuses on alternative medicine needs a qualitative study, which was beyond the scope of this study.
\end{abstract}

\section{Introduction}

India is facing the increasing burden of non-communicable diseases (NCDs). ${ }^{1}$ NCDs amount to nearly 5.87 million deaths, comprising $60 \%$ of all deaths in India. ${ }^{2}$ The main NCDs in India are cardiovascular diseases, hypertension, diabetes mellitus, chronic obstructive pulmonary diseases (COPD), and cancer. ${ }^{3}$ The behavioural risk factors having the largest contribution to NCDs morbidity and mortality are tobacco use, unhealthy diet, physical inactivity, and harmful use of alcohol. ${ }^{3}$

NCDs are a major public health problem that requires regular medication along with lifestyle modification to achieve adequate control. ${ }^{4}$ Increasingly, individuals interested in improving their health and making healthy lifestyle changes are turning to complementary and alternative medicine (CAM) as a health-care option. The global prevalence of CAM is reported to be $9.8-76.0 \%{ }^{5}$ The prevalence of use of alternative medicine usage among hypertensive, COPD, diabetes, cardiovascular disease, and cancer was documented to be $39 \%,{ }^{6} 43 \%,{ }^{7} 30 \%,{ }^{4} 30.2 \%,{ }^{8}$ and $39.1 \%,{ }^{9}$ respectively.

In India, there is a high degree of cultural diversity. To encourage indigenous systems, a separate department for Indian Systems of Medicine and Homeopathy (ISM and H), now known as AYUSH (Ayurveda, yoga, unani, siddha, homoeopathy), was created. Despite greater access to free health care facilities, a better awareness of disease problems, and pervasive contact through electronic and print media, the use of unprescribed alternative medicine is popular in India. ${ }^{4}$ The present study was done to determine the prevalence, pattern, and predictors of alternative medicine use among non-communicable disease patients undergoing allopathic treatment in an urban health centre.

\section{Design and Methods \\ This study was conducted in a health centre situated in Srikot, an urban area of Srinagar Tehsil, district Pauri Garhwal,}

Significance for public health

Alternative medicine provision for non communicable disease patients remains largely informal or unregulated. Though integrated into conventional health care frameworks it is largely fragmented. A better understanding of the pattern of alternative medicine use amongst non communicable disease patients will help dispel prevalent misconceptions concerning alternative medicine. It will assist conventional practitioners to critically evaluate their own prescribing habits. 
Uttarakhand, India. It is a hospital-based cross-sectional study conducted in 2018. The study group was adult men and women older than 20 years of age. The people having a non-communicable disease that is hypertension, diabetes, chronic obstructive pulmonary disease, cardiovascular disease, or cancer were enrolled in the study. the people who were very sick were excluded from the study. The sample size was calculated based on complementary and alternative medicine use among $30 \%$ of diabetic patients in rural Kerala, India. ${ }^{4}$ The sample size came to be 233 after taking $6 \%$ precision and a $95 \%$ confidence level. The data collection instrument was a questionnaire having patient demographics namely age, sex, marital status, literacy level, occupation, residence, religion, income and others, non-communicable disease variables namely disease, duration, health care provider, treatment and lifestyle modification, and various aspects of alternative medicine usage (types, experiences, reasons, benefits, influences, effects and consequences, source, and access to alternative medicine) ${ }^{9}$

Patients presenting to the health centre with the non-communicable disease were recruited at the registration counter. Every $\mathrm{n}^{\text {th }}$ patient was chosen after a random starting point between 1 and 10 . Houses of the patients were visited. Investigator introduced himself to the study participant before the start of the interview. Study participants were given an information sheet and they were explained regarding the study, its objectives, procedure, and the rights of the participants. If the study participant agreed to participate in the study after going through the information sheet then a written consent was taken from him/her. The studied patients were interviewed according to the questionnaire. The survey was conducted until the final sample size was achieved. Alternative medicine refers to a community of alternative methods, procedures, and products of medical and health care that are not part of conventional medicine. ${ }^{10}$ Non-communicable disease refers to known cases of cardiovascular diseases, hypertension, diabetes mellitus, chronic obstructive pulmonary diseases, and cancer. ${ }^{3}$ There are various types of alternative medicine usage by the patient of non-communicable disease, for example, medicinal herbs/biological-based medicine (aloe vera, evening primrose, turmeric, asafoetida, ginger, vitamins, etc.), spiritual therapy/mind-body systems (faith healing, divinations, meditation, hypnotherapy, etc.), alternative systems (Chinese medicine, Indian/Ayurveda medicine, acupuncture, homeopathy), physical therapy/body manipulations (chiropractic, osteopathy, massage, manual healing), energy therapies (bio-electro magnetics, oxygen/ozone treatment), local/folk remedies (ritual sacrifice, cow urine therapy, etc.). ${ }^{9}$ All the data was entered into Microsoft Excel 2010. SPSS version 20 was used for statistical analysis. Graphs were produced using Microsoft EXCEL software after obtaining the relevant information from the SPSS output. To obtain frequency tables and diagrams, descriptive techniques were used. An inferential method was used for the association between selected socio-demographic or other attribute variables and alternative medicine use. Logistic regression was used to identify predictors of alternative medicine use. A p-value lower than 0.05 was considered to be statistically significant. Ethical clearance was received from the Institute Ethics committee.

\section{Results}

The overall response rate was $89.6 \%$. The major reason for non-response was the lack of availability of the patient's time. A total of 233 patients were studied, $57.1 \%$ were males and $42.9 \%$ were females. The majority $(45.9 \%)$ of the studied patients were of the age group 21-40 years. The mean age was 55.8 years for the surveyed patients (SD 13.5). The age was recorded as reported by the studied patients. Out of the 233 , more than three fourth $(79.8 \%)$ of the patients studied were married. Out of the 233, studied patients, more than half of males studied intermediate or higher. On the other hand, only $34 \%$ of females had studied intermediate or higher. Overall, almost $16 \%$ of studied patients studied less than primary class. Among males, 34.6\% were shopkeepers or businessmen, $30.1 \%$ had a private or government job; on the contrary among females nearly half $(41.0 \%)$ were housewives. The mean family income of the study participant was Rs 29162.3.1(SD 26276.6), respectively; the average family size was 4.04(SD 2.3) members and nearly $67.4 \%$ of the studied patients had a nuclear family. Of the total, $96.6 \%$ of the studied patients were Hindu. The mean per capita income was Rs 8575.8 (SD 6659.9); using the revised modified BG Prasad socioeconomic classification scale, January 2018 , it was found $48.5 \%$ of the studied patients belonged to the upper class (Rs 6574 and above) and 34.8\% to the uppermiddle class (Rs 3287-6573). Of the total studied patients $46.8 \%$ were diagnosed with diabetes mellitus, and $43.8 \%$ with hypertension. Nearly one-fifth of the patients were known to have cardiovascular disease or chronic lung disease. Among all the patients over two-third were seeking health care services from the public health facility only. Overall 29 patients presented with more than one non-communicable disease and 5 patients presented with more than two non-communicable diseases (Table 1). A total of $49.8 \%$

Table 1. Distribution of studied patients by non-communicable disease.

\begin{tabular}{|c|c|c|c|c|c|c|c|c|c|c|c|}
\hline Non-com & nicable d & & & $\begin{array}{r}\text { Duratior } \\
\text { (y }\end{array}$ & VCD & & & h ca & prov & & \\
\hline Category & Status & n & $\%$ & Mean & SD & & & & & & \\
\hline & & & & & & n & $\%$ & n & $\%$ & $n$ & $\%$ \\
\hline Diabetes mellitus & Present & 109 & 46.8 & & & & & & & & \\
\hline & Absent & 124 & 53.2 & 9.58 & 9.07 & 74 & 67.9 & 20 & 18.3 & 15 & 13.7 \\
\hline Hypertension & Present & 102 & 43.8 & & & & & & & & \\
\hline & Absent & 131 & 56.2 & 6.49 & 5.78 & 79 & 77.4 & 12 & 11.8 & 11 & 10.8 \\
\hline Cardiovascular disease & Present & 30 & 12.9 & & & & & & & & \\
\hline & Absent & 203 & 87.1 & 4.6 & 4.04 & 22 & 73.3 & 5 & 16.7 & 3 & 10 \\
\hline Chronic lung disease & Present & 20 & 8.6 & & & & & & & & \\
\hline & Absent & 213 & 91.4 & 8.44 & 7.82 & 16 & 80 & 0 & 0 & 4 & 20 \\
\hline Cancer & Present & 1 & 0.4 & & & & & & & & \\
\hline & Absent & 232 & 99.6 & 8 & 0 & 1 & 100 & 0 & 0 & 0 & 0 \\
\hline
\end{tabular}

NCD, non-communicable disease. 
of the studied NCD patients reported use of both allopathic and alternative medicine treatment and nearly $3.4 \%$ of the studied noncommunicable disease patients in the last one year to seek exclusive alternative medicine treatment. More than half of the studied patients having diabetic and chronic lung disease used both allopathic and alternative medicine treatment. The overall use of exclusive alternative medicine was low that is $3.7 \%, 1.0 \%$, and $5 \%$ in diabetes, hypertension, and chronic lung disease patients, respectively (Table 2). Of the total 196 (84.1\%) studied patients reported one or other lifestyle modification adopted. The most common lifestyle modifications adopted were salt restriction (43.4\%), 30 min of brisk walking or exercise per day (40.3\%), and Dietary modification (33.7\%).

The most common form of alternative medicine used by studied patients was medicinal herbs/biological-based medicine (62.9\%). Among medicinal herbs/biological-based medicine commonly used were a bitter gourd, aloe vera, and others. This was fol- lowed by alternative systems. The most common alternative system used was Indian/Ayurveda medicine. Overall 29.8\% of the studied patients used Indian/Ayurveda medicine. Nearly one-fifth of the patients practice spiritual therapy/mind-body systems, and local/folk remedies, respectively (Table 3 ).

Medicinal herbs/biological-based medicine was the most common form of alternative medicine used by patients with diabetes. The commonly used medicinal herbs/biological-based medicine were bitter gourd, fenugreek, aloe vera, and others. Nearly half of the diabetic patients reported the use of two or more alternative medicines. Nearly one-fourth of the hypertensive patients reported use of each medicinal herbs/biological-based medicine and alternative system, respectively. The commonly used medicinal herbs/biological-based medicine among hypertensive were asafetida, giloy, bitter gourd, turmeric, tulsi, ginger, and others. Among cardiovascular disease and chronic lung disease, medicinal herbs/biological-based medicine was most commonly used.

Table 2. Prevalence of alternative medicine use among adult Non-communicable disease patients in last one year ( $\mathrm{n}=233)$.

\begin{tabular}{|c|c|c|c|c|c|c|}
\hline \multirow[t]{2}{*}{ Non-communicable disease } & \multicolumn{2}{|c|}{ Allopathic } & \multicolumn{2}{|c|}{$\begin{array}{c}\text { Treatment } \\
\text { Alternative medicine }\end{array}$} & \multicolumn{2}{|c|}{ Both } \\
\hline & n & $\%$ & n & $\%$ & n & $\%$ \\
\hline Diabetes mellitus $n=109$ & 45 & 41.3 & 4 & 3.7 & 60 & 55.0 \\
\hline Hypertension $n=102$ & 58 & 56.8 & 1 & 1.0 & 43 & 42.2 \\
\hline Cardiovascular disease $n=30$ & 17 & 56.7 & 0 & 0.0 & 13 & 43.3 \\
\hline Chronic lung disease $n=20$ & 8 & 40.0 & 1 & 5.0 & 11 & 55.0 \\
\hline Cancer $n=1$ & 1 & 100.0 & 0 & 0.0 & 0 & 0 \\
\hline Total & 109 & 46.8 & 8 & 3.4 & 116 & 49.8 \\
\hline
\end{tabular}

Total is higher than the number of studied patients ( $\mathrm{n}=233$ ) as 29 patients presented with more than one non-communicable disease and 5 patients presented with more than two non-communicable diseases.

Table 3. Pattern of alternative medicine use among adult non-communicable disease patients in the last year ( $\mathrm{n}=124)$.

\begin{tabular}{|c|c|c|}
\hline Type of alternative medicine* & n & $\%$ \\
\hline Medicinal herbs/biological-based medicine* & 78 & 62.9 \\
\hline Bitter gourd & 31 & 39.7 \\
\hline Aloe vera & 16 & 20.5 \\
\hline Fenugreek seeds & 15 & 19.2 \\
\hline Turmeric & 10 & 12.8 \\
\hline Ginger & 10 & 12.8 \\
\hline Kedar Kadwi & 9 & 11.5 \\
\hline Asafoetida & 9 & 11.5 \\
\hline Giloyi & 8 & 10.3 \\
\hline Neem & 6 & 7.7 \\
\hline Others (roots of basingha, kirmod, jamun, garlic, daal chini, alsi ka tel, tulsi, papaya leaves, kotki roots, evening primose) & 16 & 20.5 \\
\hline Spiritual therapy/mind-body systems* & 25 & 20.2 \\
\hline Divinations & 1 & 4.0 \\
\hline Meditation & 20 & 80.0 \\
\hline Others & 6 & 24.0 \\
\hline Alternative systems* & 44 & 35.5 \\
\hline Indian/Ayurveda medicine & 37 & 84.1 \\
\hline Homeopathy & 8 & 18.2 \\
\hline Physical therapy/body manipulations* & 1 & 0.8 \\
\hline Manual healing & 1 & 100.0 \\
\hline Local/folk remedies* & 25 & 20.2 \\
\hline Ritual sacrifice & 2 & 8.0 \\
\hline Cow urine therapy & 5 & 20.0 \\
\hline Others & 19 & 76.0 \\
\hline
\end{tabular}

*Multiple answers. 
Local/Folk remedies were practiced high among patients having chronic lung disease (Table 4).

The three most common reasons were desire to try everything that could help (39.5\%), the side effects of allopath $(21.8 \%)$, and allopath was too expensive (14.5\%), respectively. Other reasons reported by the patient with the non-communicable disease for using alternative medicine: disappointed with allopath, alternative medicine was more in keeping with personal beliefs and the inner self, allopath was often not in free supply, allopath was not accessible, and others.

The source of awareness about alternative medicine was primarily family members $(33.1 \%)$, this was followed by friends (26.6\%), mass media (27.4\%), and health personnel (16.9\%). Most commonly family members (33.9\%) influenced the studied patients to use alternative medicine. Only one-fourth of the total studied patients were influenced by health personnel $(24.2 \%)$ patients to use alternative medicine.

Overall nearly half $(52.4 \%)$ of the studied patients were satisfied with the use of alternative medicine. Approximately twothirds $(62.1 \%)$ of the studied patients perceived the benefits of using alternative medicine. Alternative medicine was easily accessible to about two-third (63.7\%) of the studied patients. Of the total $29 \%$ of the studied patients reported the side effects of alternative medicine usage (Table 5). Nearly one-fifth of the studied patients using alternative medicine was not aware of the level of experience with alternative medicine use. Similarly around one-fifth of studied patients were not sure of any benefits or side effects of alternative medicine use.

Table 6 shows the prevalence of alternative medicine use was nearly equally distributed among males and females. More than two-thirds $(67.7 \%)$ of patients using alternative medicine literacy status were secondary school or less. Prevalence of alternative medicine use was higher among patients aged less than 60 years. Prevalence of alternative medicine use was almost thrice among patients belonging to upper or upper-middle socioeconomic class. More than two-thirds $(66.1 \%)$ of alternative medicine users had nuclear families. The unadjusted and adjusted odds ratios for fac- tors associated with the use of alternative medicine among adult patients with the non-communicable disease was done. On univariate analysis age in years, sex, literacy status, occupation, socioeconomic status, type of family, and marital status was not found to be significantly associated with $\mathrm{p}<0.05$. Multiple logistic regression with entry and removal probability of 0.05 and 0.20 , respectively revealed no studied variable as significantly associated with increased risk use of alternative medicine among adult patients with the non-communicable disease $(\mathrm{p}<0.05)$.

\section{Discussion}

This study was done to determine the prevalence of alternative medicine use among non-communicable disease patients undergoing allopathic treatment in an urban health centre in Srinagar, Garhwal, Uttarakhand. The present study enrolled 233 adult noncommunicable disease patients. Females constituted nearly half of the study population. More than half of the males studied intermediate or higher. Overall, around one-fifth of the study patients, only $34 \%$ of females had studied intermediate or higher. Overall, almost $16 \%$ studied less than the primary class. Similar was the finding of the DLHS III survey, which mentioned 79.1 percent population in Uttarakhand had schooling of 7 years or more. ${ }^{11}$ Among males, approximately one-third were shopkeepers or businessmen, and another one-third were engaged in private or government jobs whereas nearly half of the females were homemakers. More than half of the studied patients belonged to the upper-middle or upper class. This indicates the study population was literate and had good economic status.

In the present study, of the total studied patients, $46.8 \%$ were diagnosed with diabetes mellitus, $43.8 \%$ with hypertension, and others with cardiovascular disease, chronic lung disease, and cancer. Over two-thirds of the studied patients were seeking health care services from the public health facility only. The prevalence of alternative medicine use among non-communicable disease

Table 4. Distribution of alternative medicine use by type of Nnn-communicable disease among studied patients in last year.

\begin{tabular}{|c|c|c|c|c|c|c|c|c|}
\hline \multirow[t]{3}{*}{ Alternative treatment pattern } & \multirow{2}{*}{\multicolumn{2}{|c|}{$\begin{array}{c}\text { Diabetes } \\
\text { mellitus } \\
n=64\end{array}$}} & \multicolumn{4}{|c|}{ Non-communicable disease } & \multirow{2}{*}{\multicolumn{2}{|c|}{$\begin{array}{c}\text { Chronic } \\
\text { lung disease } \\
\mathrm{n}=12\end{array}$}} \\
\hline & & & \multicolumn{2}{|c|}{$\mathrm{n}=44$} & \multicolumn{2}{|c|}{$\begin{array}{c}\text { Cardiovascular } \\
\text { disease } \\
n=13\end{array}$} & & \\
\hline & n & $\%$ & n & $\%$ & n & $\%$ & n & $\%$ \\
\hline Medicinal herbs/biological-based medicine & 22 & 34.4 & 13 & 29.5 & 4 & 30.8 & 2 & 16.7 \\
\hline Spiritual therapy/mind-body systems & 3 & 4.7 & 6 & 13.6 & 1 & 7.7 & 0 & 0.0 \\
\hline Alternative systems & 8 & 12.5 & 12 & 27.3 & 2 & 15.4 & 3 & 25.0 \\
\hline Physical therapy/body manipulations & 0 & 0.0 & 0 & 0.0 & 1 & 7.7 & 0 & 0.0 \\
\hline Local/folk remedies & 0 & 0.0 & 3 & 6.8 & 1 & 7.7 & 1 & 8.3 \\
\hline $\begin{array}{l}\text { Medicinal herbs/biological-based medicine + } \\
\text { spiritual therapy/mind-body systems }\end{array}$ & 12 & 18.8 & 1 & 2.3 & 2 & 15.4 & 1 & 8.3 \\
\hline $\begin{array}{l}\text { Medicinal herbs/biological- based medicine + } \\
\text { Alternative systems }\end{array}$ & 10 & 15.6 & 4 & 9.1 & 0 & 0.0 & 1 & 8.3 \\
\hline Medicinal herbs/biological- based medicine + local/folk remedies & 9 & 14.1 & 2 & 4.5 & 1 & 7.7 & 3 & 25.0 \\
\hline Combination of any $\geq 3$ & 0 & 0.0 & 3 & 6.8 & 1 & 7.7 & 1 & 8.3 \\
\hline
\end{tabular}

Total is higher than the number of patients who reported the use of alternative medicine ( $\mathrm{n}=124)$ as 29 patients presented with more than one non-communicable disease and 5 patients presented with more than two non-communicable diseases. 
patients was $46.8 \%$ (CI: $40.1 \%$ to $53.1 \%$ ) in the last one year. The prevalence of exclusive alternative medicine use among non-communicable disease patients was 3.4\% (CI: $1.7 \%$ to $6.6 \%$ ) in the last one year. These findings were similar to a study that was conducted in 2002 on patients attending a health facility, Japan. ${ }^{12}$ A systematic review of 87 studies estimated the prevalence of CAM within and around EU countries, 0.3-86 percent ranged widely $(0.3-86 \%) .{ }^{13}$ Also, a community-based study, in Tanzania, in 201314 , found the prevalence of medical pluralism was $37.6 \%(95 \%$ CI 20.5-58.4\%). ${ }^{14}$ Similarly, a study from India reported the use of CAM was $58 \%$ doctors and $28 \%$ patients among 200 doctors and 403 patients at tertiary care teaching hospital. ${ }^{15}$

The prevalence of CAM use was higher in a study among Australian women aged $48-67$ years $(82 \%) .{ }^{16}$ This may be attributed to the variation in the population surveyed. The study of Australia recruited only women. Also, there is an age difference between the present study population and the above study. Another cross-sectional survey conducted in clinics found the 519 respondents reported CAM use in the past 12 months $(80.0 \%) .{ }^{17}$ The prevalence of CAM use was $62 \%$ adults during the past 12 months in a study from the USA. ${ }^{18}$ The high CAM use could be due to the involvement of all the diseases whereas the present study recruited only NCD patients. As compared to the present study lower medical pluralism was practiced by $16.1 \%$ of women with NCD in South Africa, as documented by the Prospective Urban Rural Epidemiology study. ${ }^{19}$ Another data analysis of the PURE study showed the prevalence of traditional health medicine use was $27 \%$, of which $61 \%$ was for NCDs. ${ }^{20} \mathrm{~A}$ cross-sectional study was carried out in a health care setting, in Cambodia, Vietnam, and Thailand documented the prevalence of complementary and alternative medicine was $26.0 \% .^{21}$ The primary reason could be above studies had a larger sample size and different geographical areas.

In the present study around half of the studied patients having diabetes, hypertension, cardiovascular disease, and chronic lung disease used both Allopathic and Alternative medicine treatment. The overall use of exclusive alternative medicine was low that is $3.7 \%, 1.0 \%$, and $5 \%$ in diabetes, hypertension, and chronic lung disease patients, respectively. Similarly, a cross-sectional study from outpatient diabetes departments at Governmental Hospitals in
Palestine found of 1883 patients with diabetes $51.9 \%$ reported use of CAM. ${ }^{22}$ Also a study of 225 hypertensive patients attending the hypertension clinic, in Nigeria mention $39.1 \%$ of the respondents used CAM. ${ }^{23}$ A likely study was conducted among type- 2 diabetes patients in rural Kerala to measure the prevalence of exclusive use of complementary and alternative medicine and associated factors among 400 diabetes patients selected using the multi-stage cluster sampling. The prevalence of exclusive CAM use was reported by $9 \%$, and combined use by $30 \% .{ }^{4}$ However, a cross-sectional study of 4575 patients attending outpatient hypertension clinics in Palestine found $85.7 \%$ of respondents used at least one type of CAM. ${ }^{24}$ The above difference primarily could be because of the difference in sample size. A 2015 study estimated that 75.3 percent of diabetes patients in Iran used at least one form of complementary and alternative medicine in the previous year. ${ }^{25}$ This difference could be as a present study enrolled all NCD patients. A Mexican survey showed that $97.2 \%$ of cancer patients used complementary

Table 5. Various factors for use of alternative medicine to the adult patient with the non-communicable disease $(n=124)$.

\begin{tabular}{lll} 
Domain & n & $\%$ \\
Level of experience with alternative medicine use & & \\
$\quad$ Satisfied & 65 & 52.4 \\
$\quad$ Not satisfied & 35 & 28.2 \\
$\quad$ Do not know & 24 & 19.4 \\
Perceived any benefits of alternative medicine use & & \\
$\quad$ Yes & 77 & 62.1 \\
$\quad$ No & 32 & 25.8 \\
$\quad$ Not sure & 15 & 12.1 \\
\hline Alternative medicine easily accessible & & \\
$\quad$ Yes & 79 & 63.7 \\
$\quad$ No & 45 & 36.3 \\
Side effects of alternative medicine use & & \\
$\quad$ Yes & 36 & 29.0 \\
No & 67 & 54.0 \\
$\quad$ Not sure & 21 & 16.9 \\
\hline
\end{tabular}

Table 6. Distribution of various risk factors with use of alternative medicine among adult patient with non-communicable disease.

\begin{tabular}{|c|c|c|c|c|c|c|}
\hline Variable & Category & $\begin{array}{c}\text { Alternative } \\
\text { medicine use } \\
\text { present n (\%) n=124 }\end{array}$ & $\begin{array}{l}\text { Unadjusted OR } \\
(95 \% \mathrm{CI})\end{array}$ & p & $\begin{array}{l}\text { Adjusted OR } \\
\text { (95\% CI) }\end{array}$ & p \\
\hline Age in years & $\begin{array}{l}<60 \\
\geq 60\end{array}$ & $\begin{array}{l}78(62.9) \\
46(37.1)\end{array}$ & $1.19(0.7-2.02)$ & 0.513 & $1.12(0.61-2.07)$ & 0.72 \\
\hline Sex & $\begin{array}{l}\text { Male } \\
\text { Female }\end{array}$ & $\begin{array}{l}72(58.1) \\
52(41.9)\end{array}$ & $1.09(0.65-1.83)$ & 0.74 & $0.94(0.51-1.71)$ & 0.83 \\
\hline Literacy status & $\begin{array}{l}\leq \text { secondary } \\
\geq \text { graduation }\end{array}$ & $\begin{array}{l}84(67.7) \\
40(32.3)\end{array}$ & $0.62(0.35-1.12)$ & 0.11 & $0.67(0.36-1.24)$ & 0.20 \\
\hline Occupation & $\begin{array}{l}\text { Retired/ housewife/ others } \\
\text { Employed/business/agriculture }\end{array}$ & $\begin{array}{l}67(54.0) \\
57(46.0)\end{array}$ & $1.21(0.72-2.03)$ & 0.47 & $1.09(0.57-2.11)$ & 0.78 \\
\hline Socioeconomic status & $\begin{array}{l}\leq \text { middle class } \\
\geq \text { upper class }\end{array}$ & $\begin{array}{l}20(16.1) \\
104(83.9)\end{array}$ & $0.9(0.45-1.81)$ & 0.79 & $0.99(0.48-2.03)$ & 0.98 \\
\hline Type of family & $\begin{array}{l}\text { Nuclear } \\
\text { Extended }\end{array}$ & $\begin{array}{l}82(66.1) \\
42(33.9)\end{array}$ & $0.88(0.51-1.53)$ & 0.66 & $0.65(0.33-1.30)$ & 0.22 \\
\hline Marital status & $\begin{array}{l}\text { Married } \\
\text { Others }\end{array}$ & $\begin{array}{l}99(79.8) \\
25(20.2)\end{array}$ & $1.4(0.78-2.64)$ & 0.24 & $0.79(3.74)$ & 0.16 \\
\hline
\end{tabular}


and alternative medicine. ${ }^{26}$ This difference could be because the above study was done in a cancer hospital. Other studies among hypertensive subjects in Ibadan, ${ }^{27}$ diabetics, ${ }^{28}$ chronic kidney disease, dyslipidemia, and hypertension patients in Jordan, ${ }^{24}$ and cancer patients in Amman, ${ }^{29}$ asthmatic patients in South India, ${ }^{30}$ and epilepsy, HIV, rheumatoid arthritis, and diabetes mellitus patients in India ${ }^{31}$ reported the use of complementary and alternative medicine of $29 \% 16.6 \% 29 \% 7.6 \%, 35.5 \%, 30.4 \%$, and $34.7 \%$, respectively. This difference is mainly because the above studies had disease-specific study patients or patients with other diagnoses in addition to non-communicable disease. Also, in the present study individualizing the diseases reduces the sample size.

In the present study, the most common form of alternative medicine used by non-communicable disease patients was medicinal herbs/biological-based medicine $(62.9 \%)$. Similar were the results of the study from Mexico, ${ }^{26}$ Tanzania, ${ }^{14}$ Ibadan, ${ }^{27}$ Palestine, ${ }^{24}$ Europe, ${ }^{13}$ and Australia, ${ }^{16}$ and rural India. ${ }^{30}$ Among medicinal herbs/biological-based medicine commonly used were a bitter gourd, aloe vera, and others. A study of 225 hypertensive patients stated garlic $(69.3 \%)$, ginger $(23.9 \%)$, bitter leaf $(9.1 \%)$, and aloe vera $(4.5 \%)$ were commonly used herbs. ${ }^{23}$ Another study from Tanzania also reported aloe vera as a commonly used herb.

The most common alternative system used was Indian/Ayurveda medicine. Overall $29.8 \%$ of the studied patients used Indian/Ayurveda medicine. This was similar to other studies across India. $., 15,30,31$ On the contrary the commonest form of CAM in other studies from Japan were pain relief pads $(32.8 \%),{ }^{2}$ massage $(43 \%),{ }^{12}$ and USA prayer (43.0\%). ${ }^{18}$ This difference could be due to differences in the culture of various geographical areas.

The common reasons for starting the use of alternative medicine among adult patients with non-communicable disease were: a desire to try everything that could help $(39.5 \%)$, the side effects of allopath (21.8\%), and allopath was too expensive (14.5\%), respectively. A study was carried out among 200 doctors and 403 patients at tertiary care teaching hospitals, India. The study mentioned CAM users felt that compared to allopathy, CAM is more effective, safer, less costly, and easily available. ${ }^{15}$

The source of awareness about alternative medicine was primarily family members $(33.1 \%)$, this was followed by friends $(26.6 \%)$, mass media $(27.4 \%$, ) and health personnel (16.9\%). Most commonly family members (33.9\%) influenced the studied patients to use alternative medicine. A likely study conducted among cancer patients in the private health facility in Mexico, in 2004 found the source of information about complementary and alternative medicine was the patient's family in $56.4 \%$ of CAM users. $^{26}$ In the present year, nearly half $(52.4 \%)$ of the studied patients were satisfied with the use of alternative medicine. Approximately two-thirds $(62.1 \%)$ of the studied patients perceived the benefits of using alternative medicine. Similar were the findings of a study from Mexico, ${ }^{26}$ Cambodia, Vietnam, and Thailand, ${ }^{21}$ South Africa, ${ }^{20}$ Palestine, ${ }^{22}$ Jordan $^{[29]}$, and north India. ${ }^{32}$

In the present study, the prevalence of alternative medicine use was nearly equally distributed among males and females. The prevalence of alternative medicine use was higher in patients with or below secondary school literacy, belonging to the top or uppermiddle socio-economic class, and below the age of 60 years. Similarly, a study studied in a tertiary care South Indian hospital among 394 asthmatic patients reported higher patient education and socioeconomic status was statistically relevant to CAM use. ${ }^{30}$ On the contrary, a cross-sectional survey conducted in three rural Japanese family medicine clinics among 519 stated female gender, higher literacy rate, and poor prognosis patients more likely used complementary and alternative medicine. ${ }^{17}$ Cross-sectional research was also performed in a healthcare environment, showing female gender, urban residency, residing in Vietnam, and having two or more chronic disorders in Cambodia, Vietnam, and Thailand was correlated with the increased use of complementary and alternative medicine items. ${ }^{21}$ On the contrary, another research in the Idikan population of 440 hypertensive subjects showed male gender, belief in spiritual reasons, lack of belief that hypertension can be avoided and family history of hypertension were statically relevant independent factors for CAM usage. Factors like age, educational level, and occupation were not statically significant independent factors of CAM use. ${ }^{27}$ Also, a study documented no significant difference in the clinical characteristics, socio-economic status, and blood pressure with CAM use by a study of 225 hypertensive patients attending the hypertension clinic. ${ }^{23}$ This difference in findings of various above is because of the patient's disease spectrum and the difference in sample size. An analysis estimated the use of complementary and alternative medicine by U.S. adults using data from the 2002 National Health Interview Survey found the use of CAM varied by sex, age, geographic location, and others. ${ }^{18}$ The study has its limitations as well. A better understanding of practices especially that focuses on alternative medicine needs a qualitative study, which was beyond the scope of this study.

\section{Conclusions}

The use of exclusive alternative medicine is low in adult patients of non-communicable disease in Srinagar, Garhwal, Uttarakhand. The adult patients of non-communicable disease in Srinagar, Pauri district, Garhwal region, Uttarakhand practice medical pluralism as evident from the burden of alternative medicine use along with allopathic. The commonest forms of alternative medicine used were medicinal herbs or biological-based medicine and alternative systems like Ayurveda. The important predictors of the use of alternative medicine were a desire to try alternative medicine, disappointing allopath, and the side effects of an allopath. Family members and friends are the commonest source of information and influencing factors for alternative medicine use. The prevalence of alternative medicine use was higher in patients with or below secondary school literacy, belonging to the top or upper-middle socio-economic class, and below the age of 60 years. 
Correspondence: Dr. B Venkatashiva Reddy, Associate Professor, Department of Community Medicine, NRI Academy of Medical Sciences, Guntur, Andhra Pradesh, India.

Tel. +91.9582520015. E- mail: dr.shiva222@gmail.com

Key words: Alternative; complementary; Ayurveda; non-communicable disease; hypertension; diabetes.

Contributions: VSR, study concept; DN, data collection; AG, DN, data analysis; VSR, AG, DN, manuscript original drafting, and reviewing; VSR, final draft approval. All authors of this article share the responsibility for the above. Authors declare the manuscript has been read and approved by all the authors, that the requirements for authorship have been met, and that each author believes that the manuscript represents honest work, if that information is not provided in another form.

Conflict of interest: The authors declare no conflict of interest.

Funding: The study was funded by Indian Council of Medical Research (STS 2018-03309). The funding body has no role in the design of the study and collection, analysis, and interpretation of data and in writing the manuscript.

Ethical approval: All participants in this study approved and provided their informed written consent for the authors to analyse the information retrieved from them. The informed written consent was aimed to encourage free and informed participation of the participants'. The participants were informed that their participation was completely voluntary and that the authors would ensure the confidentiality of the data provided in any of the reports that resulted from this study. The study protocol, including the use of informed written consent, was approved by the Institute Ethics Committee, Veer Chandra Singh Garhwali Government Institute of Medical Sciences and Research, Uttarakhand, India (IEC/VCSGGMSI\&R/033).

Availability of data and material: The datasets generated and/or analyzed during the current study are not publicly available due to conditions of participants' consents but are available from the corresponding author on reasonable request.

Received for publication: 12 January 2021.

Accepted for publication: 10 February 2021.

oCopyright: the Author(s), 2021

Licensee PAGEPress, Italy

Journal of Public Health Research 2021;10:2109

doi:10.4081/jphr.2021.2109

This work is licensed under a Creative Commons Attribution NonCommercial 4.0 License (CC BY-NC 4.0).

\section{References}

1. WHO. India: first to adapt the Global Monitoring Framework on noncommunicable diseases. Accessed on: January 12, 2018. Available from: http://www.who.int/features/2015/ncd-

2. WHO. NCDs and development. Accessed on: January 12, 2018. Available from: http://www.who.int/nmh/ publications/ncd_report_chapter2.pdf

3. WHO. Burden of NCDs and their risk factors in India. Accessed on: January 12, 2018. Available from: http://www.who.int/features/2015/ncd-india/en/

4. Vishnu N, Mini GK, Thankappan KR. Complementary and alternative medicine use by diabetes patients in Kerala, India. Glob Health Epidemiol Genom 2017;2:1- 7.

5. Harris PE, Cooper KL, Relton C, et al. Prevalence of complementary and alternative medicine (CAM) use by the general population: a systematic review and update. Int J Clin Pract 2012;66:924-39.

6. Amira OC, Okubadejo NU. Frequency of complementary and alternative medicine utilization in hypertensive patients attending an urban tertiary care centre in Nigeria. BMC Complement Altern Med 2007;7:30.

7. Abadoglu O, Cakmak E, Kuzucu Demir S. The view of patients with asthma or chronic obstructive pulmonary disease (COPD) on complementary and alternative medicine. Allergol Immunopathol (Madr) 2008;36:21-5.

8. Kristoffersen AE, Sirois FM, Stub T, et. al. Prevalence and predictors of complementary and alternative medicine use among people with coronary heart disease or at risk for this in the sixth Tromsø study: a comparative analysis using protection motivation theory. BMC Complement Altern Med 2017; 17:324.

9. Bahall M. Prevalence, patterns, and perceived value of complementary and alternative medicine among cancer patients: a cross-sectional, descriptive study. BMC Complement Altern Med 2017;17:345.

10. National Centre for Complementary and Alternative Medicine. The use of complementary and alternative medicine in the United States. 2008. Accessed on: January 12, 2018. Available from: https://nccih.nih.gov/research/statistics/2007/camsurvey_fs1.htm

11. District level household and facility survey. India 2007-2008. Accessed on: January 16, 2018. Available from: http://www.rchiips.org/prch-3.html

12. Hori S, Mihaylov I, Vasconcelos JC, McCoubrie M.Patterns of complementary and alternative medicine use amongst outpatients in Tokyo, Japan. BMC Complement Altern Med 2008;8:14.

13. Eardley S, Bishop FL, Prescott P, et al. A systematic literature review of complementary and alternative medicine prevalence in EU. Forsch Komplementmed 2012;19:S18-28.

14. Lunyera J, Wang D, Maro V, et al. Traditional medicine practices among community members with diabetes mellitus in Northern Tanzania: an ethnomedical survey. BMC Complement Altern Med 2016;16:282.

15. Roy V, Gupta M, Ghosh RK. Perception, attitude and usage of complementary and alternative medicine among doctors and patients in a tertiary care hospital in India. Indian J Pharmacol 2015;47:137-142.

16. Gollschewski S, Anderson D, Skerman H, Lyons-Wall P. Associations between the use of complementary and alternative medications and demographic, health and lifestyle factors in mid-life Australian women. Climacteric 2005;8:271-8.

17. Shumer G, Warber S, Motohara S, et al. Complementary and alternative medicine use by visitors to rural Japanese family medicine clinics: results from the international complementary and alternative medicine survey. BMC Complementary Altern Med 2014;14:360.

18. Barnes PM, Powell-Griner E, McFann K, Nahin RL. Complementary and alternative medicine use among adults: United States, 2002. Adv Data 2004;1-19.

19. Aboyade OM, Beauclair R, Mbamalu ON, et al. Health-seeking behaviours of older black women living with non-communicable diseases in an urban township in South Africa. BMC Complement Altern Med 2016;16:410.

20. Hughes GD, Aboyade OM, Beauclair R, et al. Characterizing 
herbal medicine use for noncommunicable diseases in urban South Africa. Evid Based Complement Alternat Med 2015;2015:736074.

21. Peltzer K, Pengpid S, Puckpinyo A, et al. The utilization of traditional, complementary and alternative medicine for noncommunicable diseases and mental disorders in health care patients in Cambodia, Thailand and Vietnam. BMC Complement Altern Med 2016;16:92.

22. Ali-Shtayeh MS, Jamous RM, Jamous RM. Complementary and alternative medicine use amongst Palestinian diabetic patients. Complement Ther Clin Pract 2012;18:16-21.

23. Amira OC, Okubadejo NU. Frequency of complementary and alternative medicine utilization in hypertensive patients attending an urban tertiary care centre in Nigeria. BMC Complement Altern Med 2007;7:30.

24. Ali-Shtayeh MS, Jamous RM, Jamous RM, Salameh NM. Complementary and alternative medicine (CAM) use among hypertensive patients in Palestine. Complement Ther Clin Pract 2013;19:256-63.

25. Hashempur MH, Heydari M, Mosavat SH, et al. Complementary and alternative medicine use in Iranian patients with diabetes mellitus. J Integr Med 2015;13:319-25.

26. Gerson-Cwilich R, Serrano-Olvera A, Villalobos-Prieto A. Complementary and alternative medicine (CAM) in Mexican patients with cancer. Clin Transl Oncol 2006;8:200-7
27. Osamor PE, Owumi BE. Complementary and alternative medicine in the management of hypertension in an urban Nigerian community. BMC Complement Altern Med 2010;10:36.

28. Wazaify M, Afif FU, El-Khateeb M, Ajlouni K. Complementary and alternative medicine use among Jordanian patients with diabetes. Complement Ther Clin Pract 2011;17:71-5.

29. Afifi FU, Wazaify M, Jabr M, Treish E. The use of herbal preparations as complementary and alternative medicine (CAM) in a sample of patients with cancer in Jordan. Complement Ther Clin Pract 2010;16:208-12.

30. Sarvesh S, Koushik Muthu Raja M, Rajanandh MG, Seenivasan P. Prevalence and pattern of usage of complementary and alternative medicine among south Indian asthma patients in a tertiary care hospital. Complement Ther Clin Pract 2018;30:103-8.

31. Bhalerao MS, Bolshete PM, Swar BD, et al. Use of and satisfaction with complementary and alternative medicine in four chronic diseases: a cross-sectional study from India. Natl Med J India 2013;26:75-8.

32. Gupta M, Shafiq N, Kumari S, Pandhi P.P atterns and perceptions of complementary and alternative medicine (CAM) among leukaemia patients visiting haematology clinic of a north Indian tertiary care hospital. Pharmacoepidemiol Drug Saf 2002;11:671-6. 